\title{
Interfirm knowledge transfer in multinational and single-country joint patenting: a technological distance analysis
}

\author{
Iryna Maliatsina \\ iryna.maliatsina@lut.fi| School of Business and Management, LUT University, Finland \\ Jaan-Pauli Kimpimäki \\ jaan-pauli.kimpimaki@lut.fi | School of Business and Management, LUT University, Finland
}

\begin{abstract}
In today's highly competitive business environment, firms can ill afford the consequences of overlooking opportunities for innovation. An organization seeking to increase its existing knowledge base, in most cases, aims to identify and pursue useful knowledge available outside its borders. However, for companies interested in engaging in collaborative arrangements for innovations, systematic approaches for knowledge transfer may become a major challenge. In our research, we focus on the diffusion of innovative knowledge that occurs during a joint knowledge development process. We conduct an empirical study of joint patent applications and patent portfolios using the PATSTAT database spanning the period from 2004 to 2018, aiming to explore the impact inter-organizational collaboration in the form of joint patenting has on the distance between partners' technological bases. In addition, we study the changes in the technological distance when joint patenting occurs within-country and between-country partners. Our results suggest that engagement in joint patenting positively influences the technological proximity between partners and indicates the transmission and utilization of knowledge outside of firms' existing knowledge bases. Our findings contribute to knowledge related to innovation under conditions of interorganizational collaboration and provide a basis for further theory development and testing.
\end{abstract}

Keywords. Inter-organizational Collaboration; Technological Distance; Joint Patent Ownership; Patent Portfolios; Finland.

Cite paper as: Maliatsina, I., Kimpimäki, J., (2020). Interfirm knowledge transfer in multinational and singlecountry joint patenting: a technological distance analysis, Journal of Innovation Management, www.open-jim.org, 8(4), 103-130. 


\section{Introduction}

It is difficult to deny that knowledge is a critical organizational asset (Tucker, Meyer and Westerman, 1996). Drawing from the knowledge-based view of the firm (Grant, 1997), organizational competencies in creating, acquiring, and transferring knowledge have become important ingredients necessary to remain competitive in today's increasingly dynamic business environment. In this context, it is not enough for organizations to rely upon internal R\&D processes (Schroll and Mild, 2011) and intraorganizational learning only to innovate effectively (Lin et al., 2013). To be truly successful in achieving innovative performance, a firm needs to continuously acquire new knowledge from external sources (Quintas, Lefrere and Jones, 1997) and to be involved in collaborative innovation (Laursen and Salter, 2006; Parida, Westerberg and Frishammar, 2012). In other words, a firm can access new knowledge and expand its existing knowledge base through the process of grafting the knowledge base of other firms onto its own (Huber, 1991; Ranft and Lord, 2002). External knowledge acquisition is not sufficient for improving a firm's innovation performance as it depends largely on the firm's own internal ability to add new knowledge to its existing knowledge base, this ability being also known as absorptive capacity (Cohen and Levinthal, 1989; Grant, 1996).

Prior research demonstrates that $R \& D$ positively affects the growth or productivity and overall innovative performance of the firm (Noel and Schankerman, 2013). The rise of the popularity of collaborative R\&D can be partially explained by high business operations risks and innovation costs (Powell, Koput and Smith-Doerr, 1996). Inter-firm collaboration may therefore accelerate joint learning and innovation processes, and result in the expansion of partners' own knowledge bases.

One of the formal measures of a firm's innovation output is its patent portfolio. A patent is a useful measure of innovation output, which is externally validated and reflects the advancements of technological evolution (Bellamy, Ghosh and Hora, 2014). Firms with a large number of patents are more likely to transform them into novel products for the market (Joshi et al., 2010). While some studies acknowledge the importance of integrating patent strategy within firm strategy (e.g. Alexy, Criscuolo and Salter, 2009; Bogers, 2011; Holgersson and Granstrand, 2017), many scholars view patent rights as a barrier to the innovation process e.g. by increasing direct and indirect costs (Cohen, Nelson and Walsh, 2000; Noel and Schankerman, 2013), or by facilitating information leakages (Takalo and Kanniainen, 2000). When deciding on whether to patent or not, individual firms make a trade-off between protecting novel knowledge and preventing knowledge leakage (Mihm, Sting and Wang, 2015). However, the motives of firms' patenting involve far more than simple protection against imitation: consideration of motives range from adopted technology strategy and level of open innovation (Holgersson and Granstrand, 2017), to offensive and defensive blockades (Blind et al., 2006) and firm reputation or technological image (Blind and Thumm, 2004).

Joint patenting - which implies that a patent is assigned to and jointly owned by more than one inventor - is relatively rare (Kim and Song, 2007). In our study, we argue that prior collaborative relationships between two companies can lead to producing new inventions, which might result in the joint patent as one of the forms of shared ownership. There is a considerable body of previous research conceptualizing interfirm knowledge exchange in the context of knowledge clusters (e.g. 
Arikan, 2009), strategic alliances (e.g. Mowery, Oxley, \& Silverman, 1996), informal know-how networks (e.g. von Hippel, 1987), and social capital (Mu, Peng and Love, 2008). However, despite the importance of understanding the impact of joint patenting on interfirm knowledge transfer, prior research has focused mostly on university-industry patenting (e.g. Petruzzelli, 2011; Kato and Odagiri, 2012; Messeni Petruzzelli and Murgia, 2020). The main motivations for this study are the lack of empirical research on (i) the existence of interfirm knowledge transfer in $R \& D$ partnerships, and (ii) the degree to which firms participating in joint patenting share and absorb the results of their joint R\&D efforts.

This paper contributes to interfirm collaboration field development by analyzing the knowledge transfer that occurs during the joint knowledge development process. To test the absorption of technological know-how and expansion of partners' technological bases, we conducted an empirical study of joint patent applications and patent portfolios spanning the period from 2004 to 2018. Our results suggest that engagement in joint patenting positively influences the technological proximity between partners and indicates the transmission and utilization of knowledge originating outside of firms' existing knowledge bases.

We organize the rest of the paper as follows. In the first section, we review the extant literature on the topic of interfirm knowledge transfer in the context of collaborative technology development and discuss the concepts of technological distance and patent portfolio. Then, we move on to discuss the methodology applied and describe the process of data collection. Next, we present our results with a comprehensive analysis of how engaging in a joint patent application influences the technological distance between partners engaging in collaborative innovation. At the end of the paper, we present our conclusions, discuss limitations, and identify future research directions.

\section{Theory and Hypotheses}

This chapter is structured in several parts: we start with a brief overview of the literature on knowledge transfer in the context of collaborative technology development, followed by a discussion on knowledge sharing in multinational and national collaborations, patent portfolios, joint patent ownership, and technological distance. At the end of this chapter, we develop and discuss our hypotheses.

\subsection{Collaborative innovation and knowledge transfer}

Kogut \& Zander (1992) described the knowledge of a firm as its ability to generate combinative capabilities toward the effective acquiring, synthesis, and application of information and know-how through a process of structured social construction embedded within the firm's operating boundaries. Within this framework, innovations are the product of the firm's combinative capabilities i.e. its ability to recognize and exploit novel combinations of under- or unexplored technologies (ibid.). This capability rests on a firm's ability to access relevant knowledge, which in turn relies on intra-firm networks of inventors and their ability to engage in collaborative knowledge-creation activities (Paruchuri and Awate, 2017). Such collaborative linkages 
collectively form networks of knowledge-transferring actors who jointly constitute the overall knowledge base for firms looking to access external knowledge (Powell, Koput and Smith-Doerr, 1996). However, such collaboration and accessibility may be problematic in practice, as most knowledge tends to be tacit until made explicit through a process of socialization and externalization (Nonaka and Konno, 1998; Lawson, Petersen, Cousins, \& Handfield, 2009) or through alternative forms of codification (Kogut \& Zander, 1992).

Knowledge made explicit may become easily transferrable, yet such transferability may not be sufficient for a firm to fully exploit acquired knowledge unless the firm further can integrate it into its operations (Grant, 1996). Higher degrees of knowledge complexity tend to increase the degree of difficulty of successfully carrying out internal knowledge transfers (Kim and Anand, 2018). Van Wijk, Jansen and Lyles (2008) have identified three categories of antecedents of organizational knowledge transfer: knowledge, organizational and network characteristics. One of the most important predictors of organizational knowledge transfer is its knowledge ambiguity (Birkinshaw, Nobel and Ridderstråle, 2002), which has been suggested to negatively affect organizational knowledge transfer (Van Wijk, Jansen and Lyles, 2008). Transferred knowledge can further be characterized based on its observability in use, which refers to the degree to which knowledge needs to be disclosed to be understood; and system embeddedness, which refers to the degree to which knowledge is related to the context in which it is embedded (Birkinshaw, Nobel and Ridderstråle, 2002). Some of the organizational predictors of knowledge transfer include firm size, age, and decentralization (Van Wijk, Jansen and Lyles, 2008). Centrality and the number of links to other firms are considered as some of the main network characteristics predictive of the degree of knowledge transfer (Gupta and Govindarajan, 2000; Tsai, 2001).

At the individual level, the main determinant of learning outcome is a person's motivation to learn; in inter-organizational collaboration and at the firm level, organizations are similarly driven by self-determination, desire, and the will to learn from the partner (Simonin, 2004). In other words, a firm's motivation to transfer knowledge from its partner can be determined by its intention to acquire a partner's specific skills and competencies (Pucik, 1988; Simonin, 2004).

To both access and integrate knowledge relevant to technological development and exploitation from external sources, a firm requires absorptive capacity, i.e. the ability "to evaluate and utilize outside knowledge" and "to recognize the value of new information, assimilate it, and apply it to commercial ends" (Cohen and Levinthal, 1989, p. 128). Or, as more recently reconceptualized, it refers to "a set of organizational routines and processes by which firms acquire, assimilate, transform, and exploit knowledge to produce a dynamic organizational capability" (Zahra and George, 2002, p. 186).

Absorptive capabilities are essential for a firm to be internally effective in technological codevelopment and R\&D collaboration - or any participation in external knowledge networks at large (Lin et al., 2012) - because without them a firm engaging in technological co-development may end up unintentionally externalizing its own knowledge through learning spillovers (Breschi, Lissoni and Malerba, 2003) while remaining unable to benefit from the same itself. The ability to appropriate knowledge is the key to generating rents and accumulatively benefiting from created knowledge and inventive work (Ahuja, Lampert and Novelli, 2013). 
The ability to benefit from external knowledge is also contingent on the firm's ability to transcend its organizational boundaries toward effectively exploring and recombing external knowledge sources to create new knowledge (Rosenkopf and Nerkar, 2001). Given sufficient absorptive capacity and ability to go beyond organizational borders, a firm may benefit from both common (one technology used for multiple purposes) and complementary (more than one technology used for a joint purpose) forms of knowledge or technology acquired from external sources (Breschi, Lissoni and Malerba, 2003).

Partner-specific absorptive capacity has been defined by Dyer and Singh (1998, p. 665) as pertaining "to the idea that a firm has developed the ability to recognize and assimilate valuable knowledge from a particular alliance partner". The formation of strategic alliances is therefore partly a firms' response to increasing overlap in knowledge bases or similar technological capabilities, as allying with partners with similar technological portfolios is more likely to increase the focal firm's partner-specific absorptive capacity and vis-à-vis each other (Mowery, Oxley and Silverman, 1996).

\subsection{Knowledge sharing in multinational and national collaborations}

In strategic alliances, Mowery, Oxley and Silverman (1996) note differences in the patterns of knowledge transfer and learning occurring in international and national collaborations. Based on their research, the authors find international collaborations less conducive to exchanges of capabilities and knowledge than national ones. These differences may be indicative of the cognitive distance (Nooteboom et al., 2007) between companies partly due to problems of understanding arising from e.g. cultural differences (Vlaar, Van Den Bosch and Volberda, 2006).

Recent research suggests that the importance of geographical proximity of collaboratively innovating partners is dependent on the type of knowledge created, with relevance being generally higher in exploration contexts and the development of radical innovations, and lower in the case of exploitative endeavors (Hinzmann, Cantner and Graf, 2019). Geographical proximity or distance is an important factor, which, may however be further mediated or complemented by other notions of distance (e.g. cognitive, organizational, or social), suggesting that effects arising from national cultural differences might to some extent be mitigated by the organizations' professional cultures (Neukam and Guittard, 2018).

\subsection{Patent portfolio and joint patent ownership}

Patent applications have been noted to be a good indicator of the technological competence of a firm, as filing a patent application implies advanced and up-to-date knowledge in a technological domain (Breschi, Lissoni and Malerba, 2003). When deciding whether to patent or not, firms consider the breadth and length of the patent, requirements of patent novelty, degree of patent protection, patent litigation, and other factors (Mihm, Sting and Wang, 2015). Previous research shows that the activity of patenting, whose original purpose was to temporarily protect a firm's innovation from replication, is nowadays used as a strategic tool for ensuring the competitiveness 
of a firm's future technological space against rivals, and as an innovation performance indicator for securing a solid business model base (Blind, Cremers and Mueller, 2009).

A patent portfolio can be defined as the collection of patents owned by a firm (Huang, 2016, p. 47). A strong patent portfolio may be used for protecting $R \& D$ efforts, revenue generation, favorable cross-licensing, and other business objectives (ibid.). Importantly, in many industries, a well- developed patent portfolio is required to access important technological know-how from external sources (Ernst, 2003). In light of world-class high-tech corporations being strategically focused on diversifying their technological competencies (Granstrand and Oskarsson, 1994), the potential of collaborative innovation development with partner with diverse and distinct patent portfolio appears important.

Joint patent applications are applications with more than one applicant company on a filing (Briggs, 2015). The joint patenting practice has traditionally been considered a secondary option only interesting after exhausting alternatives such as cross-licensing, with notable differences in practices across industries (Hagedoorn, Van Kranenburg and Osborn, 2003). Conversely, joint applications have also been found to be of generally higher quality than single applications (Briggs, 2015). The study by Hagedoorn (2003) suggests that certain industries (e.g. chemicals and pharmaceuticals) have a higher propensity to establish jointly owned patents. The same study highlights that joint patents are commonly established as a result of small-scale interorganizational $\mathrm{R} \& \mathrm{D}$ collaboration during which partners are unable to share their inventions with each other. In our study, we treat joint patent applications as formal knowledge artifacts likely arising out of more informal modes of $\mathrm{R} \& \mathrm{D}$ cooperation between related firms as argued by Hagedoorn et al. (2003), indicative of shared knowledge bases and technology overlaps.

\subsection{Technological distance}

An important factor influencing knowledge flows between organizations is their proximity to each other. Proximity contexts can range from the spatial or geographical to the social or linguistic. For instance, Guellec \& Van Pottelsberghe De La Potterie (2001) find that countries that are geographically close to each other are more likely to spawn technological collaborations given similar technological specializations or the presence of a shared language. Agrawal, Kapur, \& McHale (2008: 268) in turn found that social proximity and spatial location "substitute rather than complement one another" in inventor networks.

The notion of technological relatedness, proximity, or distance has been a point of contention for decades and has traditionally been researched through industry R\&D flows, patent distributions, bibliometrics, or patent classification schemes (Breschi, Lissoni and Malerba, 2003). Typical uses of technological distance in past research have had to do with studying spillovers (e.g. Jaffe, 1986; Stellner, 2014), mergers and acquisitions (M\&A) and strategic alliances interpreted in the context of e.g. absorptive capacity and learning (Stellner, 2014), as well as used as a measure of knowledge flows between companies (Mowery, Oxley and Silverman, 1996; Rosenkopf and Almeida, 2003).

A common assumption in the literature is that the technological distance between firms is calculable based on the vectors of relative patent class participation as a proxy for their shared 
knowledge space (Jaffe, 1986; Ahuja, 2000), where two firms that have closer relative participation over the patent class vectors are deemed similar to each other in "technological space" (Benner and Waldfogel, 2008). Typical measures for calculating the distance based on such class-vectors are their Euclidean distance (Ahuja, 2000; Rosenkopf and Almeida, 2003), their angular separation (Jaffe, 1986) also simply known as the angle (Benner and Waldfogel, 2008). As the field of technology management is growing rapidly and has attracted the attention of practitioners as well as the research community, more measures to analyze the distance of portfolios of patents have been recently developed (Stellner, 2014): e.g., the min-complement measure (Bar and Leiponen, 2012) that takes into account only the overlap in technological fields, and the Mahalanobis distance (Bloom, Schankerman and Van Reenen, 2013), which measures the proximity not only based on the patenting in the same technology field but also in related fields. The comparison of the three technological distance measures used in this study is presented in Table 1.

\subsection{Hypothesis development}

In terms of absorptive capacity, the activity of joint patenting has implications for a firm's ability to assimilate (through technological overlap) and to apply (based on access to external knowledge and patent as a formal safeguard over the developed intellectual property) external knowledge to its own operations and technological development.

Table 1. Comparison of Euclidean distance, Angular separation, and Min-complement measures applied in the present study.

\begin{tabular}{|c|c|c|c|}
\hline $\begin{array}{l}\text { Measure } \\
\text { name }\end{array}$ & Denoted & Interpretive implications & $\begin{array}{c}\text { Example } \\
\text { references }\end{array}$ \\
\hline $\begin{array}{l}\text { Euclidean } \\
\text { distance }\end{array}$ & $E$ & $\begin{array}{l}\text { Uses all information available on a vector to determine dis- } \\
\text { tances; depends on both direction and magnitude of the vec- } \\
\text { tor. As such, is subject to the curse of dimensionality and is } \\
\text { hence sensitive to firm size (vom Stein et al. 2015) i.e. the } \\
\text { more empty patent classes the compared companies have, } \\
\text { the more this measure loses in its sensitivity. The metric } \\
\text { quality awards a straightforward interpretation of distance, } \\
\text { with higher values representing a higher distance. Larger } \\
\text { companies with patents in multiple classes tend to be closer } \\
\text { as their vectors are more prone to exhibit similar profiles to } \\
\text { each other than highly focused, smaller companies. }\end{array}$ & $\begin{array}{c}\text { Ahuja, 2000; } \\
\text { Rosenkopf } \\
\text { and Almeida, } \\
2003\end{array}$ \\
\hline $\begin{array}{l}\text { Angular } \\
\text { separa- } \\
\text { tion }\end{array}$ & $A$ & $\begin{array}{l}\text { Uses only vector directions i.e. the cosine of the angle } \\
\text { between two vectors, discarding vector magnitudes in deter- } \\
\text { mining distance. Parallel vectors have an angle of } 0 \text { regardless } \\
\text { of where they exist on the vector space, hence the interpreta- } \\
\text { tion is not metric. Vectors of different magnitudes may point } \\
\text { in the same direction, so that different lengths may still yield } \\
\text { a distance of } 0 . A \text { is therefore less sensitive to biases arising } \\
\text { from differences in company sizes but does not yield a metric } \\
\text { interpretation. }\end{array}$ & $\begin{array}{l}\text { Jaffe, 1986; } \\
\text { Breschi, } \\
\text { Lissoni and } \\
\text { Malerba, } \\
2003\end{array}$ \\
\hline
\end{tabular}




\begin{tabular}{|c|c|c|c|}
\hline $\begin{array}{l}\text { Measure } \\
\text { name }\end{array}$ & Denoted & Interpretive implications & $\begin{array}{c}\text { Example } \\
\text { references }\end{array}$ \\
\hline $\begin{array}{l}\text { Min- } \\
\text { comple- } \\
\text { ment }\end{array}$ & $M$ & $\begin{array}{l}\text { Uses only patent classes regarded as relevant i.e. those clas- } \\
\text { ses that are active in both compared organizations' portfolios. } \\
\text { Satisfies a property of independence of irrelevant patent clas- } \\
\text { ses (Bar \& Leiponen, 2012), hence the relevance filter increa- } \\
\text { ses sensitivity in shared classes, but does not consider patent } \\
\text { classes that are active in one company but not the other. } \\
\text { May not be able to compare companies with small highly } \\
\text { focused patent portfolios, because such firms even in similar } \\
\text { industries may have distinct patent portfolios and therefore } \\
\text { may not have any overlapping patent classes. }\end{array}$ & $\begin{array}{c}\text { Bar and } \\
\text { Leiponen, } \\
2012 ; \text { vom } \\
\text { Stein, Sick } \\
\text { and Leker, } \\
2015\end{array}$ \\
\hline
\end{tabular}

Joint patenting increases the appropriability of the developed technology in absolute terms, but also reduces it in relative terms as a solely owned patent would award a higher degree of appropriability instead. Engaging in a joint patent application also enables participating firms to assimilate highly codified and explicit knowledge from each other within the confines of the application process. Moreover, the collaborative innovation experience associated with knowledge co-creation may further lead to the recognition of technological opportunities in the partners' technological niches. Such opportunities are likely to remain in similar technological domains, albeit potentially with alternative applications across different industries (Breschi, Lissoni and Malerba, 2003).

The rigidities and level of detail involved in the patent filing procedure necessitate a full transformation of the pertinent (and likely idiosyncratic to each party) tacit knowledge and know-how to codified explicit knowledge. When such procedures are carried out jointly between two or more companies, this explicit knowledge becomes available to all the participating parties. This required form of knowledge exchange is therefore likely to have an impact on the informal socialization of such knowledge, effectively leading to a form of knowledge spillover between the involved parties, in turn leading to an increase in their technological proximity. In view of the above discussion, we propose the following primary hypothesis:

Hypothesis 1. The technological distance between companies significantly reduces after engaging in a joint patent application.

Based on the previously discussed differences in geographical, cognitive, or social proximities in technological co-development, we further expect there to be differences between joint patent applications including only parties from one country and those including applicants from multiple countries. As former findings suggest the quality of such multinational patent applications may be higher than non-international applications - due to, for instance, increased levels of complementarity between applicant organizations from dissimilar backgrounds leading to increased novelty (Breschi, Lissoni and Malerba, 2003; Briggs, 2015) — we might expect both the underlying informal and the explicit formal relational links (Dyer and Singh, 1998) to be stronger than in solely national applications, leading to increasing degrees of closeness. As such, we propose the following hypothesis: 
Hypothesis 2. The technological distance reductions in multinational joint patent applications are more pronounced than in national joint applications.

\section{Research Design}

To address the question of how inter-organizational collaboration in joint patenting influences firms' technological distance, we conducted a large-sample study spanning the period from 2004 to 2018. We primarily considered two levels of analysis: the node-level i.e. single business firm or organization; and edge-level i.e. a pair of individual nodes linked by participation in a joint patent application.

\subsection{Data collection and measure development}

In this section we first discuss our data collection with respect to the joint patent applications, next moving on to describe the procedure for obtaining the patent portfolios for each company and their operationalization as comparable technology vectors. We then briefly present the measures chosen as indicators of the technological proximity between the companies.

Joint patent applications. To test our hypotheses, we developed five longitudinal eventbased databases using the PATSTAT database ${ }^{1}$ for each year from 2009 through 2013 . We first obtained the list of patents with more than one applicant business unit or organization. To narrow the area under study, we limited our sample to joint patents in which at least one of the assignee-organizations was registered in Finland. Finland represents one of the most innovative countries in the world (European Commission, 2019) and suits the analysis purposes in terms of sample size and representativeness. At this stage, the obtained records were transformed into an edge list in the form of a vector of pairs (i.e. vector-of-vectors) with each of the pairs representing a link established by the occurrence of a joint patent application. Where more than two companies were assigned as assignees, a full fractional counting scheme was used with all possible pair combinations within the group of applicants recorded for our analysis. To further clean the data, we removed repeating applications (here, we refer to the situation when more than one joint application was submitted between the same pair of applicants during the year) and records with universities as applicants. Additionally, each of our joint patent application records included the country of origin of the applicant. The phases of data collection and resulting samples are reported in Table 2 .

Patent portfolio. To study the change in the technological distance between two organizations jointly applying for patents, we obtained the unit level data on the number of patents owned by each organization in each patent category during five years before and after the event of the joint patent application (see Table 3). We decided to aggregate the data across the five-year period to reduce biases arising from the proximity measures following a recommendation by Benner and Waldfogel (2008).

$1 \quad$ PATSTAT Global contains bibliographical data relating to more than 100 million patent documents from leading industrialized and developing countries. Source: https://www.epo.org/searching-for-patents/business/ patstat.html\#tab-1 
Table 2. Joint patent sample data.

\begin{tabular}{lcccccc}
\hline & $\mathbf{2 0 0 9}$ & $\mathbf{2 0 1 0}$ & $\mathbf{2 0 1 1}$ & $\mathbf{2 0 1 2}$ & $\mathbf{2 0 1 3}$ \\
\hline All patents filed during the year & 2302605 & 2481525 & 2790197 & 3119105 & 3299367 \\
\hline \begin{tabular}{l} 
Total number of applicants \\
\hline
\end{tabular} & 7052702 & 7768603 & 8888579 & 10207758 & 11063003 \\
\hline $\begin{array}{l}\text { Number of patents with at least } \\
\text { two applicant-organizations with } \\
\text { at least one Finnish applicant }\end{array}$ & 364 & 304 & 296 & 458 & 700 \\
\hline $\begin{array}{l}\text { Number of companies in the final } \\
\text { sample }\end{array}$ & 220 & 177 & 215 & 63 & 142 \\
\hline $\begin{array}{l}\text { Number of edges (pairs of appli- } \\
\text { cants) in the final sample }\end{array}$ & 149 & 122 & 165 & 71 & 102 \\
\hline
\end{tabular}

The PATSTAT database is published twice a year; the data used in this study was extracted from the 2019 Autumn Edition. Taking into consideration the lag between application and publication of patents, we covered the period from 2004 until 2018 as the patent data for the year 2019 had incomplete information at the time of data collection.

PATSTAT uses the International Patent Classification (IPC) scheme, which consists of approximately 70000 distinct IPC codes for different technical areas. The data included records across the four-digit patent classes (approximately 600 dimensions) for each company in the sample. A key decision involved in the operationalization of technological profiles of companies arises in the selection of the level of aggregation of patent classes, where different choices may yield rather different results and lead to various biases (Benner and Waldfogel, 2008; Stellner, 2014). Beyond the choice of preferable patent class aggregation, we opted for the four-digit classification over higher-levels of aggregation (three- and fewer digit classes) to more fully and accurately locate the patent portfolios of companies in the technological space.

Technological distance. Changes in the technological distance between pairs of companies participating in the joint patent application were measured through the change in the distance between their patent portfolios located in knowledge space represented as technology vectors.

Table 3. Patent portfolio sample data.

\begin{tabular}{|c|c|c|c|c|c|}
\hline & \multicolumn{4}{|c|}{ Year of joint patent application } & \multirow[b]{2}{*}{2013} \\
\hline & 2009 & 2010 & 2011 & 2012 & \\
\hline $\begin{array}{l}\text { Total number of pa- } \\
\text { tents applied by all } \\
\text { companies in the sam- } \\
\text { ple before the joint } \\
\text { patent application }\end{array}$ & 197969 & 140956 & 253283 & 149996 & 631369 \\
\hline $\begin{array}{l}\text { Total number of pa- } \\
\text { tents applied by all } \\
\text { companies in the sam- } \\
\text { ple after the joint pa- } \\
\text { tent application }\end{array}$ & 173162 & 88382 & 176956 & 107160 & 451612 \\
\hline
\end{tabular}


Based on obtained records on the number of patents in each patent category applied by the company before and after a joint patent application we developed for each company a patent portfolio vector $P$ that specifies the share of its patents in each of the relevant patent classes. Considering the size effect and following Leydesdorff, Kushnir, and Rafols (2014) and Benner and Waldfogel's (2008) recommendations, we normalized the number of patents in each of the four-digit patent classes over the total number of patents applied per year by every organization in our sample, so that each firm's technology vector sums to one and each vector component stands for the relative proportion of a patent class over all classes. To evaluate changes in the technological distance we applied three distinct measures: (i) Euclidean distance; (ii) angular separation, and (iii) mid-complement. We used several measures intending to avoid a potential single-measure problem of validity (Diamantopoulos et al., 2012).

The Euclidean distance $\left(E_{i j}\right)$ is measured by comparing firms' technology vectors. Technological proximity between firms $i$ and $j$ is therefore defined as

$$
E_{i j}=\sqrt{\sum_{c=1}^{N}\left(p_{c i}-p_{c j}\right)^{2}}
$$

where $N$ is the number of dimensions (patent classes) in the partition, $p$ is the share of the firm's knowledge in each of the patent classes, and $c$ is a particular patent class (Benner and Waldfogel, 2008). In our study, $N$ is equal to approx. 600 as we are analyzing the four-digit class patent portfolio.

The angular separation $\left(A_{i j}\right)$ (also known as cosine distance or uncentered correlation index) measures the degree to which firms' technology vectors point in the same direction while controlling for vector length (Jaffe, 1986; Stellner, 2014). The angular separation between firms $i$ and $j$ can be measured as

$$
A_{i j}=\frac{\sum_{c=1}^{N} p_{c i} p_{c j}}{\sqrt{\sum_{c=1}^{N} p_{c i}^{2} \sum_{c=1}^{N} p_{c j}^{2}}}
$$

where indices are summed over the $N$ dimensions (Stellner, 2014).

The min-complement $\left(M_{i j}\right)$ is a newer alternative measure that takes into account the overlap in relevant technological fields discarding obsolete classes with no relevant representation pertaining to a pair of observed companies (Bar and Leiponen, 2012). The share is calculated as

$$
M_{i j}=1-\sum_{c=1}^{n} \min \left\{p_{i c}, p_{j c}\right\}
$$

The min-complement ranges from 0 to 1 , where 0 denotes the closest distance (Bar \& Leiponen, 2012).

\section{Results}

We adopted multiple statistical methods to analyze the data collected and the measures obtained. In the following sub-sections, we begin with brief descriptive statistics of our dataset. We then continue by presenting the statistical methods applied and present the results from our hypothesis testing. 


\subsection{Descriptive statistics}

In this section, we display descriptive statistics of our sample and illustrate the landscape of the companies investigated with network figures over joint patenting activity for each year of joint patent data collection. Table 4 shows the geographical distribution of the origins of the patent applications in our data. The most frequent inter-organizational collaboration in our sample happens among company pairs where both parties are established and registered in Finland. The table further shows that the most frequent international research collaboration occurred between Finnish and United States-based, as well as between Finnish and Germanybased organizations.

Table 4. Frequency table of the geographic distribution of the origins of the patent applications.

\begin{tabular}{|c|c|c|c|c|c|c|c|c|c|c|c|}
\hline & & \multicolumn{10}{|c|}{ Number of joint patent applications } \\
\hline & & \multicolumn{2}{|c|}{2009} & \multicolumn{2}{|c|}{2010} & \multicolumn{2}{|c|}{2011} & \multicolumn{2}{|c|}{2012} & \multicolumn{2}{|c|}{2013} \\
\hline & & $\mathbf{N}$ & $\%$ & $\mathbf{N}$ & $\%$ & $\mathbf{N}$ & $\%$ & $\mathbf{N}$ & $\%$ & $\mathbf{N}$ & $\%$ \\
\hline FI & FI & 52 & 34.90 & 51 & 41.80 & 44 & 26.67 & 15 & 21.13 & 36 & 35.29 \\
\hline FI & $\mathrm{DE}$ & 15 & 10.07 & 8 & 6.56 & 8 & 4.85 & 1 & 1.41 & 7 & 6.86 \\
\hline FI & US & 12 & 8.05 & 5 & 4.10 & 10 & 6.06 & 5 & 7.04 & 9 & 8.82 \\
\hline FI & GB & 9 & 6.04 & 2 & 1.64 & 0 & 0.00 & 0 & 0.00 & 3 & 2.94 \\
\hline FI & $\mathrm{AT}$ & 8 & 5.37 & 5 & 4.10 & 0 & 0.00 & 0 & 0.00 & 0 & 0.00 \\
\hline FI & JP & 3 & 2.01 & 3 & 2.46 & 8 & 4.85 & 0 & 0.00 & 0 & 0.00 \\
\hline FI & $\mathrm{SE}$ & 3 & 2.01 & 5 & 4.10 & 6 & 3.64 & 2 & 2.82 & 2 & 1.96 \\
\hline FI & $\mathrm{CA}$ & 3 & 2.01 & 0 & 0.00 & 0 & 0.00 & 1 & 1.41 & 0 & 0.00 \\
\hline FI & FR & 2 & 1.34 & 3 & 2.46 & 15 & 9.09 & 2 & 2.82 & 3 & 2.94 \\
\hline FI & IT & 1 & 0.67 & 2 & 1.64 & 2 & 1.21 & 3 & 4.23 & 1 & 0.98 \\
\hline FI & $\mathrm{CN}$ & 1 & 0.67 & 0 & 0.00 & 1 & 0.61 & 2 & 2.82 & 0 & 0.00 \\
\hline FI & PL & 0 & 0.00 & 2 & 1.64 & 3 & 1.82 & 2 & 2.82 & 1 & 0.98 \\
\hline FI & $\mathrm{BR}$ & 0 & 0.00 & 0 & 0.00 & 1 & 0.61 & 0 & 0.00 & 0 & 0.00 \\
\hline FI & $\mathrm{NL}$ & 0 & 0.00 & 5 & 4.10 & 0 & 0.00 & 1 & 1.41 & 7 & 6.86 \\
\hline \multicolumn{2}{|c|}{ Other } & 40 & 26.85 & 31 & 25.41 & 67 & 40.61 & 37 & 52.11 & 33 & 32.35 \\
\hline
\end{tabular}

Note: FI - Finland; DE - Germany; US - United States; GB - United Kingdom; AT-Austria; JP Japan; SE - Sweden; CA - Canada; FR - France; IT - Italy; CN - China; PL - Poland; BR - Brazil; NL - Netherlands

Table 5 shows the means, standard deviations, and minimum and maximum values for the before and after groups spanning five-years in both directions from each baseline year of our hypothesis testing data. As shown, the mean of Euclidean distance between the organizations in our sample before and after the joint patenting activity decreased for all years in our sample. The means for angular separation and min-complement are lower after joint patent activity than before, 
a) $N=220$

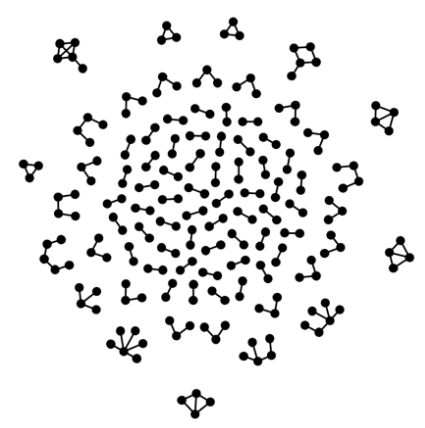

d) $N=63$ b) $N=177$

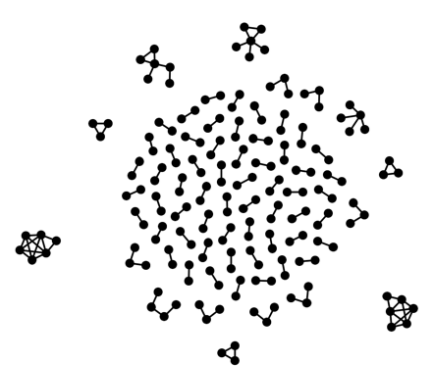

e) $N=142$ c) $N=215$

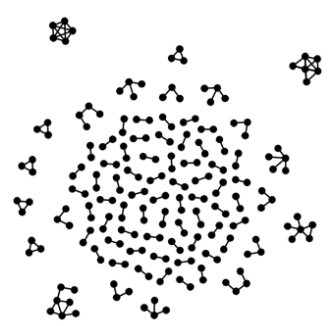

璃


Fig. 1. Force Atlas layout of joint patent applications for year a) 2009; b) 2010; c) 2011; d) 2012; e) 2013 (Force Atlas layout; attraction strength 10.0; gravity 30; prevent overlap)

showing the results are inconsistent across the years. The reason for this inconsistency might be found in the relatively high variability of the data.

We transformed the dataset into the Pajek-compatible .net format to import it into Gephi, open-source software for exploring and manipulating networks (Bastian and Heymann, 2009). To spatialize these networks for improved readability, we applied the ForceAtlas graph layout which is a force-directed layout algorithm natively implemented in the Gephi software (Jacomy et al., 2014). Figure 1 shows the network layouts of the companies linked through participation in joint patent applications for each sampled year, 2009 through 2013. The visualizations reveal that the networks are highly clustered with most of the nodes being pairwise-connected only, indicating that the majority of organizations in our sample are linked to only one partner. However, there are also several denser zones and larger clusters with more than three companies linked to each other on the outer rings of the nets.

Figure 2 in turn displays the distributions of data for each measure (Euclidean distance $E$, angular separation $A$, and min-complement $M$ ) applied over each year of data collected, with the $y$-axes standing for a number of companies and the $x$-axes for measured values. Figure 2 shows that the data in our sample is not normally distributed, and in the case of angular separation and min-complement are significantly right-skewed (positive skewness). 


\subsection{Results of analysis}

To test our hypotheses, we considered and chose statistical tests considering the characteristics of our data and purpose of analysis. As seen in Figure 2, the data in our sample is non-normally distributed. In addition to visually analyzing the distribution of data through histograms, we conducted a Shapiro-Wilk normality test (Shapiro and Wilk, 1972), which further confirmed that our data distribution does not follow the bell-shape (symmetrical about the mean). Although non-parametric tests are typically less powerful and less flexible than their parametric counterparts (McCrum-Gardner, 2008), we decided not to transform the data because of the relatively small sample size. Therefore, instead of a paired samples t-test and an independent samples t-test, as our parametric assumptions were not satisfied, we first used the Wilcoxon signed-rank test to compare the before and after groups, and a Mann-Whitney U-test to compare independent groups. In our testing procedure, we used MATLAB to calculate the proximity measures and run the analyses for our hypothesis testing.

Wilcoxon signed-rank test. The Wilcoxon signed-rank test is used to compare two paired samples when data is measured on an interval scale but the assumption of normality for a paired t-test is not satisfied (McCrum-Gardner, 2008). The purpose of this test is to check for the hypothesis of whether the median difference in two paired samples is equal to zero. Notably, the Wilcoxon signed-rank test has a limitation of zero value difference in the pair reducing the power of the test, which is relevant for our data and should be considered while interpreting the findings of the analysis. We applied the Wilcoxon signed-rank test with the null hypothesis H0: the median is equal to zero $(M=0)$ and alternative H1: the median is lower than zero $(M$ $<0)$. Column six of Table 5 shows the $p$-values of the one-sided performance test at the $\alpha=$ 0.05 significance level. The results partially support our hypothesis 1 , in that select measures in select years show evidence of statistically significant decreases of technological distance over the sample groups. For instance, in the total sample group over the year 2011 both Euclidean distance $E$ and the Min-complement $M$ show such effects at the significance level of 0.01 . In 2010 in turn, the angular separation and min-complement show statistically significant effects at varying significance levels $(p=0.04$ for $A ; p=0.00$ for $M)$. In 2012, only the Euclidean distance $E$ shows a statistically significant effect $(p=0.00)$. The results for the years 2009 and 2013 indicate weak evidence against the null hypothesis. Therefore, even though the distance between companies participating in joint patenting is mostly reduced, the decrease has been statistically significant in only a number of cases. We could explain the lack of statistical evidence by the reduced power of the test and suggest for future research to aim at collecting data samples without narrowing at the country level.

To test the hypothesis of the impact of multi-country origins of joint patent applicants on technological distance change, we created an additional grouping variable taking the value ' 1 ' if both of the applicants were from the same country, and value ' 2 ' in case of a multi-country application. The differences in results between groups are shown in Table 6 columns from 4 to 7 . The results indicate limited support for our hypothesis 2 , in that in statistically significant cases the effects of multi-country co-ownership of applications seem to be stronger than in national applications. However, the evidenced support for both of our hypotheses remains limited, as not all groups across all years support the hypothesized relationships in a consistent manner. 


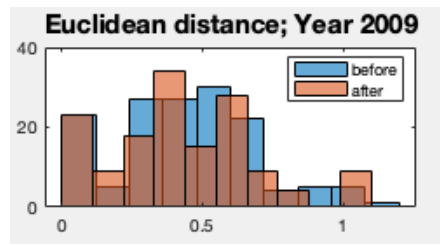

Euclidean distance; Year 2010

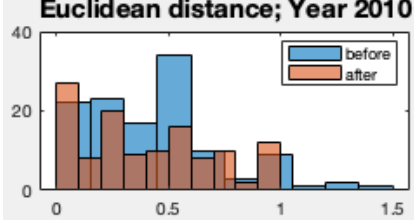

Euclidean distance; Year 2011

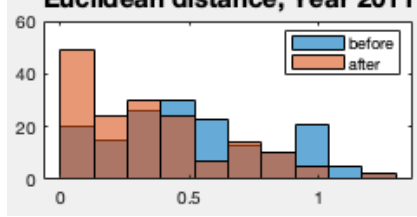

Euclidean distance; Year 2012

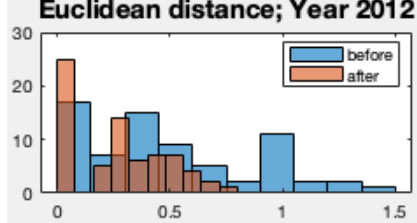

Euclidean distance; Year 2013

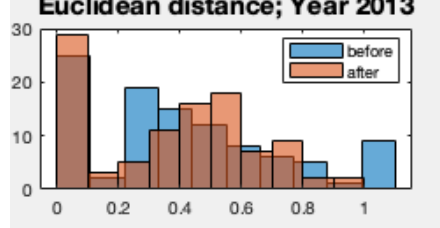

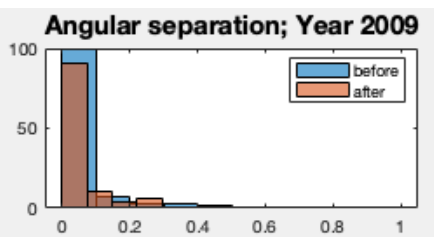

Angular separation; Year 2010
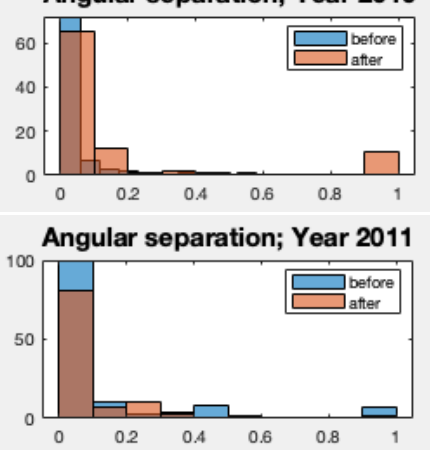

Angular separation; Year 2012
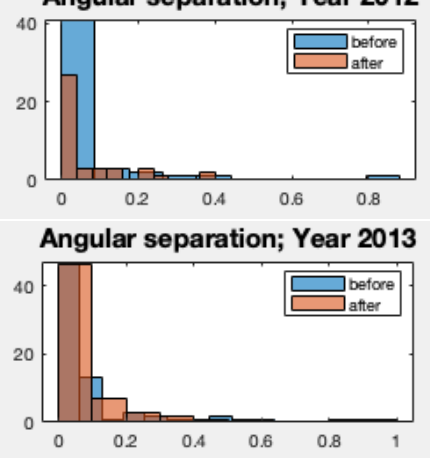

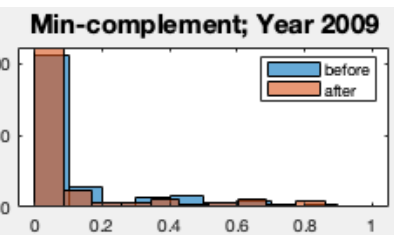

Min-complement; Year 2010

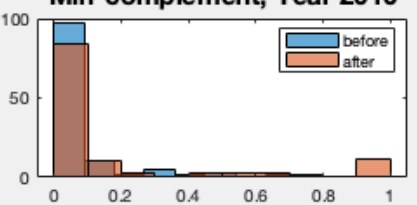

Min-complement; Year 2011

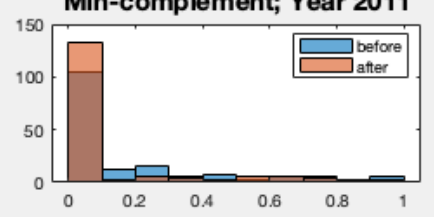

Min-complement; Year 2012

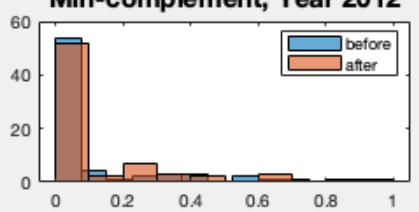

Min-complement; Year 2013



Fig. 2. Distribution of distance measures before and after joint patent application (skewed) for (a) year 2009, (b) year 2010, (c) year 2011, (d) year 2012, (e) year 2013.

Mann-Whitney U-test. In addition to the Wilcoxon signed-rank test, a Mann-Whitney Utest was used to determine whether there is a statistically significant difference in technological distance change between the two independent groups: empirical and control groups. The MannWhitney U-test is a nonparametric test for the equality of population medians of two independent samples. Prior to running the test, we generated a control group for each dataset by randomly linking the nodes in our sample. Then we separated the two groups for analysis by creating a grouping variable and encoding the control group with a value of '1-Random' and the empirical sample group with a value of '2-Sample'. The null hypothesis for the test H1: there is no significant difference in distance change between empirical and control groups $\left(M_{1}=M_{2}\right)$ and alternative $\mathrm{H} 0$ : there is a statistically significant difference $\left(M_{1} \neq M_{2}\right)$.

Prior to running the test, we obtained the descriptive statistics for our control and empirical groups. We display the means, standard deviations, and minimum and maximum values of these 


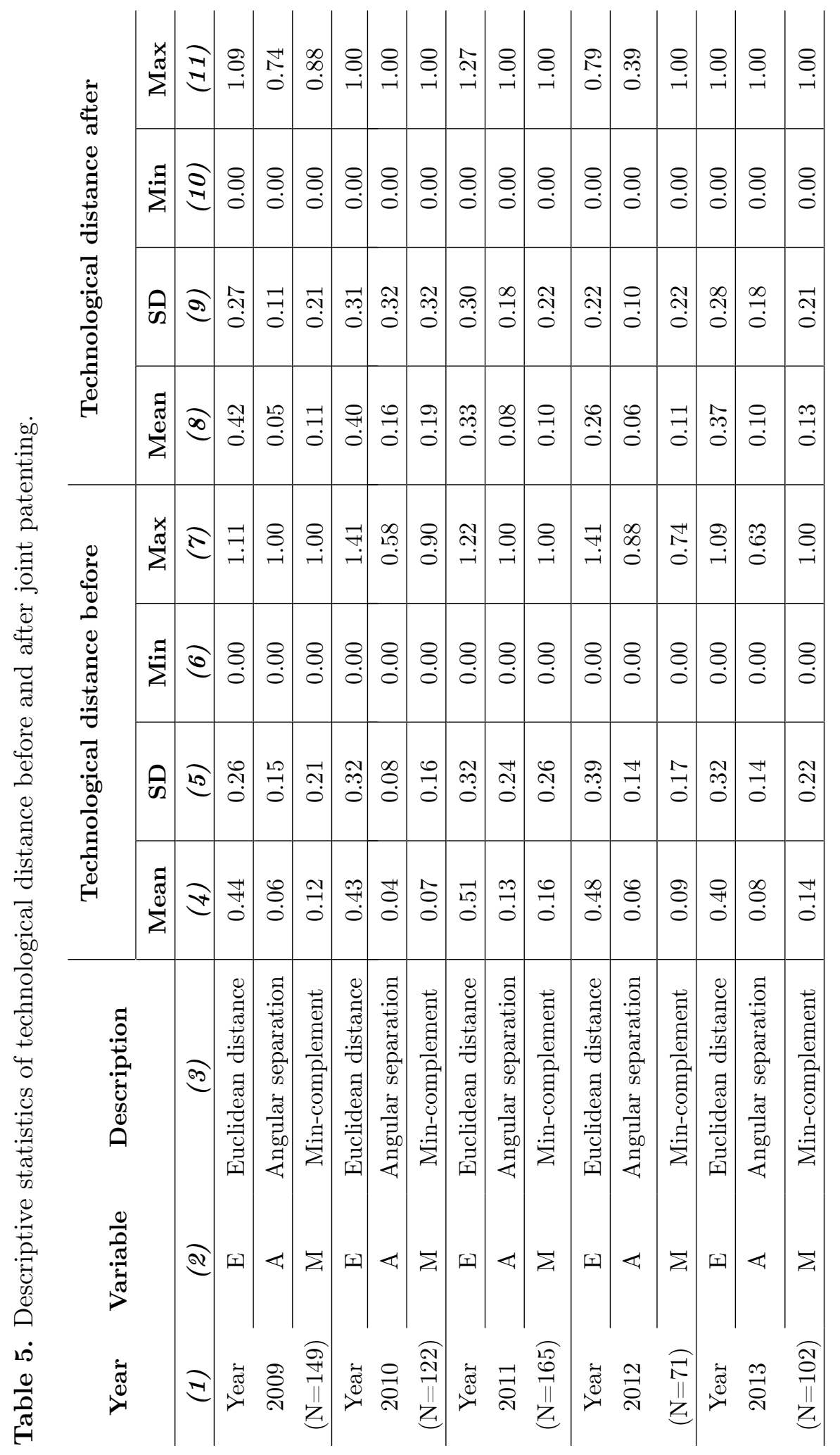




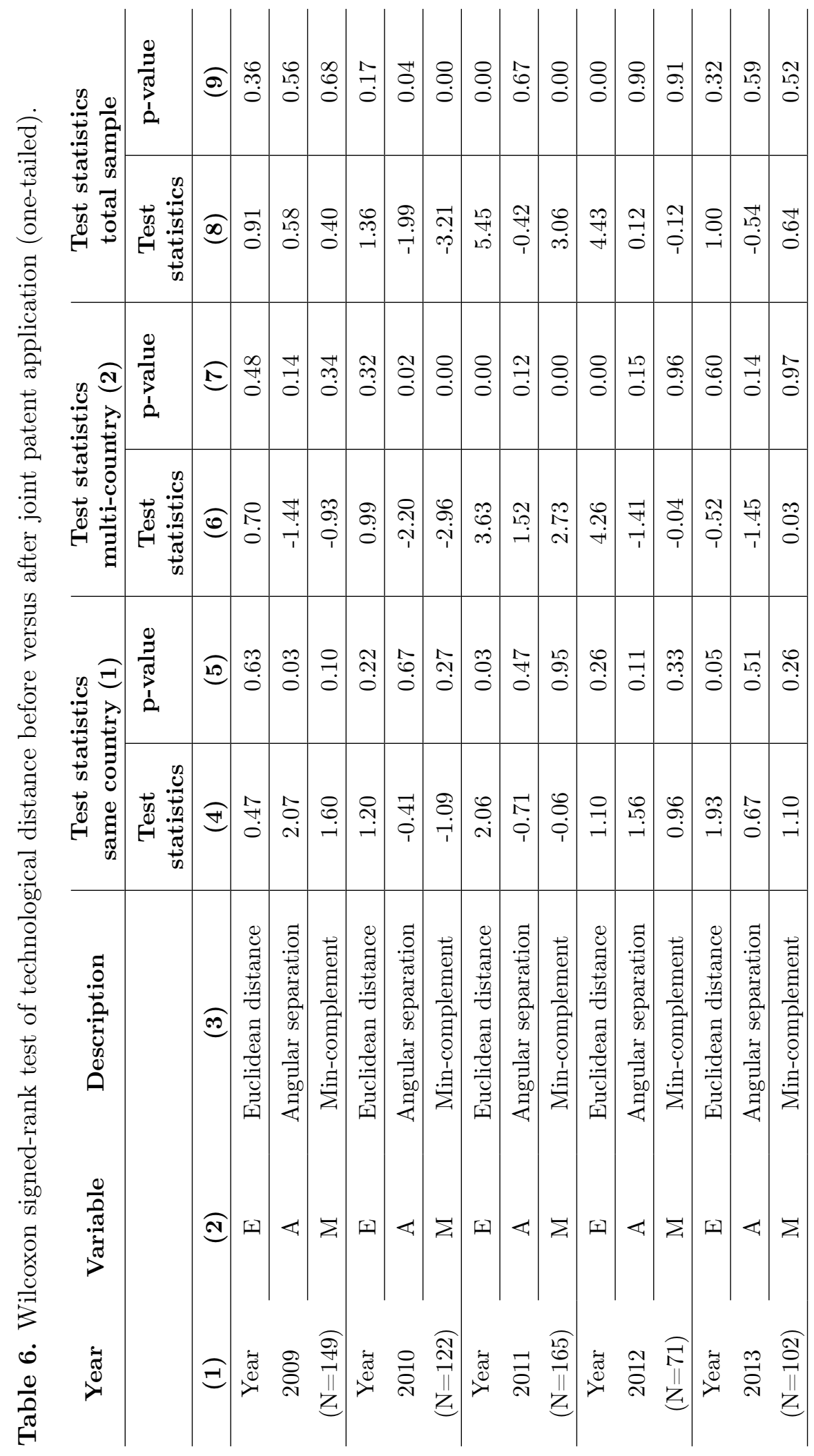


groups for each sampled year in Table 7. The mean and standard deviation between the control and empirical groups correspond to each other in most of the cases in our sample.

The results of the Mann-Whitney U-test are reported in Table 8 below. The fifth column shows the $p$-values of the two-sided performance test at the $\alpha=0.05$ significance level. According to the findings, distance change in the case of the empirical group significantly differs from the change in the control group in the years 2009 to 2011 (for the year $2009 p=0.001$ for $M$; for the year $2010 p=0.03$ for $E$ and $p=0.05$ for $M$; for the year $2011 p=0.01$ for $E$ ). For the years 2012 and 2013, we found insufficient evidence for rejecting the null $(p>0.05)$.

\subsection{Summary of analysis}

Although we received only limited support for both of our hypotheses, the results of our analysis are relatively consistent. Hypothesis 1 is partially supported by the Wilcoxon signed-rank test and Mann-Whitney U-test result for the years 2009, 2010, and 2011. Collectively, results suggest that the technological distance before the joint patent activity is larger than after for the organizations in our sample. However, although the mean distance reduces, the results are statistically insignificant for the years 2012 and 2013. Hypothesis 2 was also partially supported by the results of the Wilcoxon signed-rank test, indicating that the technological distance reductions in multinational joint applications are more pronounced than in national joint applications.

\section{Discussion}

Although our hypotheses were only partially confirmed, we note that the technological distance between companies engaging in joint patenting activities tends to reduce. Notably, while our results vary in significance between different measures of distance applied, in most cases remain consistent in direction. We believe that our findings were able to partially capture the diffusion of innovative knowledge taking place during joint knowledge production processes. With these reservations in mind, we suggest that participation in joint patenting often leads to an increase in proximity between partners' knowledge bases i.e., to an increased technological overlap between them. Increases in technological overlap may be associated with higher technological capabilities achieved by companies through collaborative technology development processes (Sears and Hoetker, 2014). We therefore posit that joint patent applications can serve as a partial proxy for an increasing degree of technological proximity between companies, especially where their initial cognitive distance is high (Nooteboom et al., 2007), and when they have no prior collaboration experience with each other. These conditions may yield on average higher degrees of complementarity, and as such lead to greater degrees of novelty. Moreover, we can endeavor to explain the ranging nature of our findings by the differences in the absorptive capacities of the sampled companies. While some firms participating in collaborative knowledge creation can effectively identify the potential in partners' technological field and utilize the gained experience to penetrate new fields of knowledge, others might not be capable of such due to their relatively low absorptive capacity. Therefore, even though we hypothesized a significant change, we cannot expect all the firms in the population to benefit from these activities in the same fashion. 


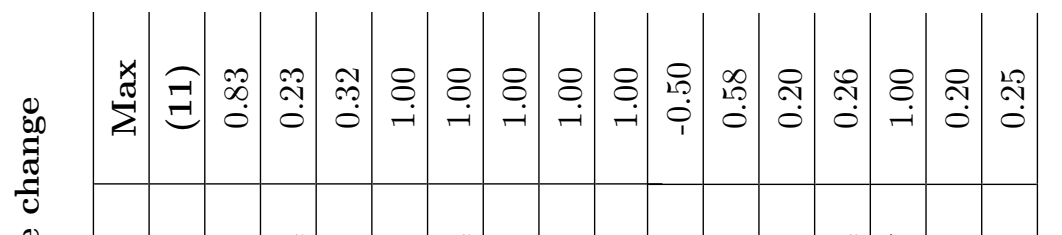

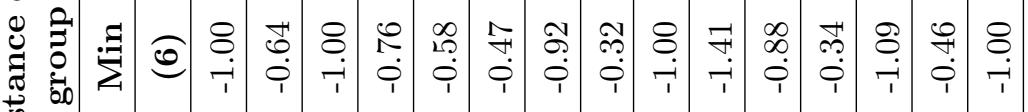

藏

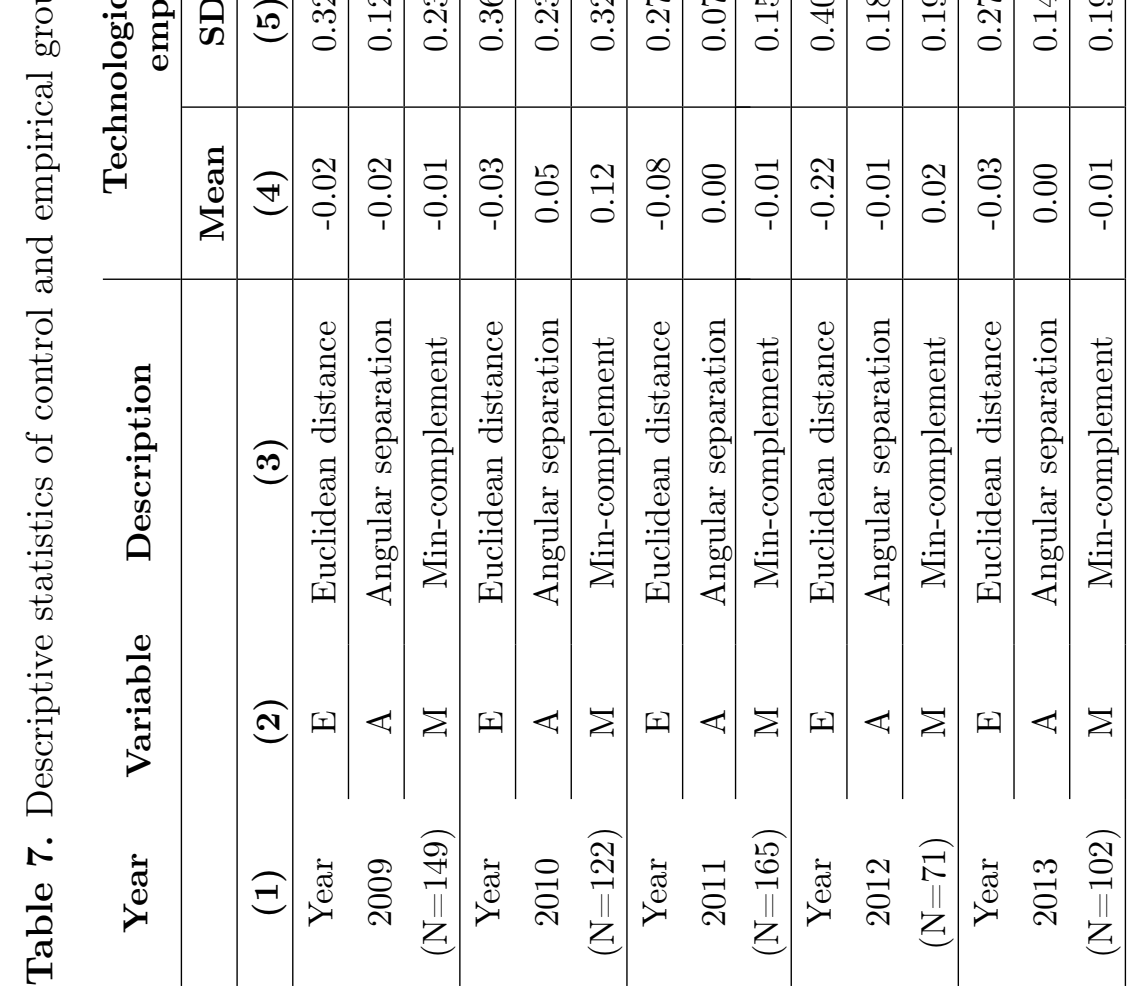


Table 8. Mann-Whitney U-test of technological distance for control and empirical groups (twotailed).

\begin{tabular}{|c|c|c|c|c|}
\hline Year & Variable & Description & $\begin{array}{c}\text { Test statistics } \\
\text { (z-value) }\end{array}$ & p-value \\
\hline$(1)$ & $(2)$ & $(3)$ & $(4)$ & $(5)$ \\
\hline \multirow[t]{3}{*}{ Year $2009(\mathrm{~N}=149)$} & $\mathrm{E}$ & Euclidean distance & 0.25 & 0.80 \\
\hline & A & Angular separation & -5.60 & 0.00 \\
\hline & M & Min-complement & 0.83 & 0.41 \\
\hline \multirow[t]{3}{*}{ Year $2010(\mathrm{~N}=122)$} & $\mathrm{E}$ & Euclidean distance & 2.09 & 0.03 \\
\hline & A & Angular separation & -0.96 & 0.33 \\
\hline & M & Min-complement & -1.95 & 0.05 \\
\hline \multirow[t]{3}{*}{ Year $2011(\mathrm{~N}=165)$} & $\mathrm{E}$ & Euclidean distance & -2.67 & 0.01 \\
\hline & A & Angular separation & 0.41 & 0.67 \\
\hline & M & Min-complement & 0.42 & 0.67 \\
\hline \multirow[t]{3}{*}{ Year $2012(\mathrm{~N}=71)$} & $\mathrm{E}$ & Euclidean distance & 0.29 & 0.76 \\
\hline & $\mathrm{A}$ & Angular separation & -0.71 & 0.47 \\
\hline & M & Min-complement & 0.06 & 0.95 \\
\hline \multirow[t]{3}{*}{ Year $2013(\mathrm{~N}=102)$} & $\mathrm{E}$ & Euclidean distance & 0.00 & 0.99 \\
\hline & A & Angular separation & -0.44 & 0.66 \\
\hline & M & Min-complement & 0.32 & 0.75 \\
\hline
\end{tabular}

Further, our findings regarding multi-country joint patenting as a factor strengthening the convergence of technological proximity lead to an interesting consideration. Previous research suggests that larger cognitive distances between $\mathrm{R} \& \mathrm{D}$ collaborators may yield increased degrees of novelty and idiosyncratic resource combinations leading to increasingly valuable inventions (Nooteboom et al., 2007; Briggs, 2015). We suggest that the greater technological distance change observed in the case of multi-national applications can be potentially explained by differences in the national innovation systems of their countries of origin. Therefore, our findings support the notion that technological collaboration of organizations from dissimilar backgrounds can result in higher novelty, than in the case of partners from similar backgrounds (Breschi, Lissoni and Malerba, 2003; Briggs, 2015). In addition, our study contributes to the methodological literature on patent data used for measuring technological distance utilizing various popular class-based measures. The results differ slightly between the various distance measures applied, indicating and supporting previous research suggesting that the choice of measure in class-based vector comparisons is an important factor when conducting patent-based analysis toward measuring technological proximity (vom Stein, Sick and Leker, 2015). In general, we find the Euclidean distance measure $(E)$ to be the most varied and evenly distributed across the sample but returning slightly less consistent results, while both the angular separation $(A)$ and min-complement $(M)$ display markedly similar results with select exceptions. 


\subsection{Limitations and Future Research}

In terms of limitations, we first note that patents per se are a highly formal security arrangement from the relational perspective (Dyer and Singh, 1998), and as such, the study of other more informal forms of safeguarding relational rents (such as trust-building) may provide supporting insights into our area of study. However, previous research also suggests that in particular joint patents are likely to arise as a result of such informal ties pertaining to research and development $(\mathrm{R} \& \mathrm{D})$ typically occurring in high-tech sectors as a result of small-scale joint development projects, where the sharing of intellectual property rights between partners is a precondition for participation and the ability to separate rights remains inaccessible (Hagedoorn, 2003). Nevertheless, an applied for joint patent does not necessarily indicate that innovative collaboration prior to issuing a formal patent application has been significant enough to affect the knowledge base of the partners. Therefore, the validity of joint patents for capturing the knowledge transfer needs to be further examined using exploratory case-study research. Further, the concepts of technological proximity and cognitive distance between companies are multidimensional, and individual measures such as class-based patent measures can only yield partially valid proxies for the phenomena at large. As such, our findings and their implications are limited to being derived from a highly formal relational dimension (patent-class overlaps and joint patent applications) of the technological relatedness and knowledge use of companies, and should therefore be interpreted with care and ideally in conjunction with former qualitative research made on the topic.

Partially, the reductions in technological distance could be explained by the self-fulfilling nature of the method in which the mechanisms under scrutiny by default reduce the measured outcome. In other words, the joint patent application itself converges the two companies profiles by the amount of the specific joint patent application in the shared class, this effect then scaling higher the fewer patent activities the compared companies have overall in their portfolios. The described size effect, therefore, tends to have a minimal impact on companies with large patent portfolios and may disproportionately affect those relationships with relatively few involved patents.

Our study serves as an interesting starting point for both further empirical testing and theory development toward explaining why exactly joint patenting might lead to increased technological proximity and under what conditions. As such, qualitative research into the translation of informal to formal modes of relational cooperation or their interaction would return interesting insights into how technological co-development might result in a co-evolutionary feedback loop between the participating companies, one shaping the other and vice versa.

Additional research could focus on investigating technological proximity in both informal and formal contexts across various degrees of $R \& D$ intensity and technological propensity, investigating whether e.g. low-tech sectors enjoy the different engagement and proximity patterns to high-tech sectors and whether cross-sector collaboration spawns different types of knowledge artifacts and informal knowledge socialization processes than collaboration occurring within a sector. Former findings suggesting the complementarity between cognitively distant actors (whether geographically or socially induced) might result in higher degrees of novelty (Nooteboom et al., 2007), subsequently suggests the hypothesis that cross-sector co-development across sectors-implying 
higher cognitive distances between partners - might yield on average higher quality joint patents than single sector joint applications between partners from the same sector.

\section{Conclusions}

In this paper, our interest was in researching the changes in technological distance resulting from companies engaging in joint patent applications. The results of our study partly support the notion that engagement in joint patenting positively influences the knowledge proximity between partners and can indicate a transfer and utilization of knowledge outside of firms' existing technological portfolio. Additionally, our research discusses how technological distance reductions in multinational joint applications are more pronounced than in national joint applications. We believe that our findings contribute to knowledge related to the innovation inter-organizational collaboration and can provide some interesting insights into future research.

\section{References}

Agrawal, A., Kapur, D. and McHale, J. (2008). How do spatial and social proximity influence knowledge flows? Evidence from patent data, Journal of Urban Economics, 64(2), 258-269.

Ahuja, G. (2000). Collaboration networks, structural holes, and innovation: A longitudinal study, Administrative Science Quarterly, 45(3), 425-455.

Ahuja, G., Lampert, C. M. and Novelli, E. (2013). The second face of appropriability: Generative appropriability and its determinants, Academy of Management Review, 38(5), 248-269.

Alexy, O., Criscuolo, P. and Salter, A. (2009). Does IP strategy have to cripple open innovation?, MIT Sloan Management Review, 51(1), 71.

Arikan, A. T. (2009). Interfirm knowledge exchanges and the knowledge creation capability of clusters, Academy of Management Review, 34(4), 658-676.

Bar, T. and Leiponen, A. (2012). A measure of technological distance, Economics Letters. Elsevier B.V., 116(3), 457-459.

Bastian, M. and Heymann, S. (2009). Gephi: An Open Source Software for Exploring and Manipulating NetworksBastian, Mathieu, and Sebastien Heymann, "Gephi: An Open Source Software for Exploring and Manipulating Networks", 2009, Quality and Safety in Health Care, 8(2009), 361-362.

Bellamy, M. A., Ghosh, S. and Hora, M. (2014). The influence of supply network structure on firm innovation, Journal of Operations Management, 32(6), 357-373.

Benner, M. and Waldfogel, J. (2008). Close to you? Bias and precision in patent-based measures of technological proximity, Research Policy, 37(9), 1556-1567.

Birkinshaw, J., Nobel, R. and Ridderstråle, J. (2002). Knowledge as a contingency variable: 
Do the characteristics of knowledge predict organization structure?, Organization Science, 13(3), $274-289$.

Blind, K. et al. (2006). Motives to patent: Empirical evidence from Germany, Research Policy, $35(5), 655-672$.

Blind, K., Cremers, K. and Mueller, E. (2009). The influence of strategic patenting on companies' patent portfolios, Research Policy, 38(2), 428-436.

Blind, K. and Thumm, N. (2004). Interrelation between patenting and standardisation strategies: Empirical evidence and policy implications, Research Policy, 33(10), 1583-1598.

Bloom, N., Schankerman, M. and Van Reenen, J. (2013). Identifying Technology Spillovers and Product Market Rivalry, Econometrica, 81(4), 1347-1393.

Bogers, M. (2011). The open innovation paradox: Knowledge sharing and protection in R\&D collaborations, European Journal of Innovation Management, 14(1), 93-117.

Breschi, S., Lissoni, F. and Malerba, F. (2003). Knowledge-relatedness in firm technological diversification, Research Policy, 32(1), 69-87.

Briggs, K. (2015). Co-owner relationships conducive to high quality joint patents, Research Policy, 44(8), 1566-1573.

Cohen, W. M. and Levinthal, D. A. (1989). Innovation and Learning: The Two Faces of R \& D, The Economic Journal, 99(397), 569.

Cohen, W. M., Nelson, R. R. and Walsh, J. P. (2000). Protecting Their Intellectual Assets: Appropriability Conditions and Why U.S. Manufacturing Firms Patent (or Not), New York.

Diamantopoulos, A. et al. (2012). Guidelines for choosing between multi-item and single-item scales for construct measurement: A predictive validity perspective, Journal of the Academy of Marketing Science, 40(3), 434-449.

Dyer, J. H. and Singh, H. (1998). The relational view: Cooperative strategy and sources of interorganizational competitive advantage, Academy of Management Review, 23(4), 660-679.

Ernst, H. (2003). Patent information for strategic technology management, World Patent Information, 25(3), 233-242.

European Commission (2019). European Innovation Scoreboard 2019, Publications Office of the European Union.

Granstrand, O. and Oskarsson, C. (1994). Technology Diversification in "MUL-TECH" Corporations, IEEE Transactions on Engineering Management, 41(4), 355-364.

Grant, R. M. (1996). Toward a knowledge-based theory of the firm, Strategic Management Journal, 17(S2), 109-122.

Grant, R. M. (1997). The knowledge-based view of the firm: Implications for management practice, Long Range Planning, 30(3), 450-454.

Guellec, D. and Van Pottelsberghe De La Potterie, B. (2001). The internationalisation of technology analysed with patent data, Research Policy, 30(8), 1253-1266. 
Gupta, A. K. and Govindarajan, V. (2000). Knowledge flows within multinational corporations, Strategic Management Journal, 21(4), 473-496.

Hagedoorn, J. (2003). Sharing intellectual property rights - An exploratory study of joint patenting amongst companies, Industrial and Corporate Change, 12(5), 1035-1050.

Hagedoorn, J., Van Kranenburg, H. and Osborn, R. N. (2003). Joint patenting amongst companies - Exploring the effects of inter-rirm R\&D partnering and experience, Managerial and Decision Economics, 24(2-3), 71-84.

Hinzmann, S., Cantner, U. and Graf, H. (2019). The role of geographical proximity for project performance: evidence from the German Leading-Edge Cluster Competition, Journal of Technology Transfer, 44(6), 1744-1783.

von Hippel, E. (1987). Cooperation between rivals: Informal know-how trading, Research Policy, $16,291-302$.

Holgersson, M. and Granstrand, O. (2017). Patenting motives, technology strategies, and open innovation, Management Decision, 1-27.

Huang, J. Y. (2016). Patent portfolio analysis of the cloud computing industry, Journal of Engineering and Technology Management - JET-M, 36, 45-64.

Huber, G. P. (1991). Organizational Learning: The Contributing Processes and the Literatures, Organization Science, 2(1), 88-115.

Jacomy, M. et al. (2014). ForceAtlas2, a continuous graph layout algorithm for handy network visualization designed for the Gephi software, PLoS ONE, 9(6), p. p.e98679.

Jaffe, A. B. (1986). Technological Opportunity and Spillovers of $R$ \& $D$ : Evidence from Firms' Patents, Profits, and Market Value, The American Economic Review. Cambridge.

Joshi, K. D. et al. (2010). Changing the competitive landscape: Continuous innovation through IT-enabled knowledge capabilities, Information Systems Research, 21(3), 472-495.

Kato, M. and Odagiri, H. (2012). Development of university life-science programs and universityindustry joint research in Japan, Research Policy, 41(5), 939-952.

Kim, C. and Song, J. (2007). Creating new technology through alliances: An empirical investigation of joint patents, Technovation, 27(8), 461-470.

Kim, S. and Anand, J. (Jay) (2018). Knowledge complexity and the performance of inter-unit knowledge replication structures, Strategic Management Journal, 39(7), 1959-1989.

Kogut, B. and Zander, U. (1992). Knowledge of the Firm, Combinative Capabilities, and the Replication of Technology, Organization Science, 3(3), 383-397.

Laursen, K. and Salter, A. (2006). Open for innovation: The role of openness in explaining innovation performance among U.K. manufacturing firms, Strategic Management Journal, 27(2), $131-150$.

Leydesdorff, L., Kushnir, D. and Rafols, I. (2014). Interactive overlay maps for US patent (USPTO) data based on International Patent Classification (IPC), Scientometrics, 98(3), 1583-1599. 
Lin, C. et al. (2012). The alliance innovation performance of R\&D alliances - The absorptive capacity perspective, Technovation, 32(5), 282-292.

Lin, H. E. et al. (2013). Managing the exploitation/exploration paradox: The role of a learning capability and innovation ambidexterity, Journal of Product Innovation Management, 30(2), $262-278$.

McCrum-Gardner, E. (2008). Which is the correct statistical test to use?, British Journal of Oral and Maxillofacial Surgery, 46(1), 38-41.

Messeni Petruzzelli, A. and Murgia, G. (2020). University-Industry collaborations and international knowledge spillovers: a joint-patent investigation, Journal of Technology Transfer, 45(4), 958-983.

Mihm, J., Sting, F. J. and Wang, T. (2015). On the effectiveness of patenting strategies in innovation races, Management Science, 61(11), 2662-2684.

Mowery, D. C., Oxley, J. E. and Silverman, B. S. (1996). Strategic alliances and interfirm knowledge transfer, Strategic Management Journal, 17(S2), 77-91.

$\mathrm{Mu}$, J., Peng, G. and Love, E. (2008). Interfirm networks, social capital, and knowledge flow, Journal of Knowledge Management, 12(4), 86-100.

Neukam, M. and Guittard, C. (2018). Reach for the stars: knowledge sharing in international organizations, Journal of Innovation Economics $\mathcal{E}$ Management, 27(3), 9-35.

Noel, M. and Schankerman, M. (2013). Strategic patenting and software innovation, Journal of Industrial Economics, 61(3), 481-520.

Nonaka, I. and Konno, N. (1998). The concept of "Ba": Building a foundation for knowledge creation, California Management Review, 40(3), 40-54.

Nooteboom, B. et al. (2007). Optimal cognitive distance and absorptive capacity, Research Policy, 36(7), 1016-1034.

Parida, V., Westerberg, M. and Frishammar, J. (2012). Inbound Open Innovation Activities in High-Tech SMEs: The Impact on Innovation Performance, Journal of Small Business Management, 50(2), 283-309.

Paruchuri, S. and Awate, S. (2017). Organizational knowledge networks and local search: The role of intra-organizational inventor networks, Strategic Management Journal, 38(3), 667-675.

Petruzzelli, A. M. (2011). The impact of technological relatedness, prior ties, and geographical distance on university-industry collaborations: A joint-patent analysis, Technovation, 31(7), 309-319.

Powell, W. W., Koput, K. W. and Smith-Doerr, L. (1996). Interorganizational collaboration and the locus of innovation: Networks of learning in biotechnology, Administrative Science Quarterly, 41, 116-145.

Pucik, V. (1988). Strategic alliances, organizational learning, and competitive advantage: The HRM agenda, Human Resource Management, 27(1), 77-93. 
Quintas, P., Lefrere, P. and Jones, G. (1997). Knowledge management: A strategic agenda, Long Range Planning, 30(3), 385-391.

Ranft, A. L. and Lord, M. D. (2002). Acquiring new technologies and capabilities: A grounded model of acquisition implementation, Organization Science, 13(4), 420-441.

Rosenkopf, L. and Almeida, P. (2003). Overcoming local search through alliances and mobility, Management Science, 49(6), 751-766.

Rosenkopf, L. and Nerkar, A. (2001). Beyond local search: Boundary-spanning, exploration, and impact in the optical disk industry, Strategic Management Journal, 22(4), 287-306.

Schroll, A. and Mild, A. (2011). Open innovation modes and the role of internal R\&D: An empirical study on open innovation adoption in Europe, European Journal of Innovation Management, 14(4), 475-495.

Sears, J. and Hoetker, G. (2014). Technological overlap, technological capabilities, and resource recombination in technological acquisitions, Strategic Management Journal, 35(1), 48-67.

Shapiro, S. S. and Wilk, M. B. (1972). An Analysis of Variance Test for the Exponential Distribution (Complete Samples), Technometrics, 14(2), 355-370.

Simonin, B. L. (2004). An empirical investigation of the process of knowledge transfer in international strategic alliances, Journal of International Business Studies, 35(5), 407-427.

vom Stein, N., Sick, N. and Leker, J. (2015). How to measure technological distance in collaborations - The case of electric mobility, Technological Forecasting and Social Change, 97, $154-167$.

Stellner, F. (2014). Technological distance measures: Theoretical foundation and empirics, DRUID Society Conference 2014.

Takalo, T. and Kanniainen, V. (2000). Do patents slow down technological progress? Real options in research, patenting, and market introduction, International Journal of Industrial Organization, 18(7), 1105-1127.

Tsai, W. (2001). Knowledge transfer in intraorganizational networks: Effects of network position and absorptive capacity on business unit innovation and performance, Academy of Management Journal, 44(5), 996-1004.

Tucker, M. L., Meyer, G. D. and Westerman, J. W. (1996). Organizational communication: Development of internal strategic competitive advantage, Journal of Business Communication, 33(1), 51-69.

Vlaar, P. W. L., Van Den Bosch, F. A. J. and Volberda, H. W. (2006). Coping with problems of understanding in interorganizational relationships: Using formalization as a means to make sense, Organization Studies, 27(11), 1617-1638.

Van Wijk, R., Jansen, J. J. P. and Lyles, M. A. (2008). Inter- and intra-organizational knowledge transfer: A meta-analytic review and assessment of its antecedents and consequences, Journal of Management Studies, 45(4), 830-853. 
Zahra, S. A. and George, G. (2002). Absorptive capacity: A review, reconceptualization, and extension, Academy of Management Review, 27(2), 185-203. 


\section{Biographies}



Iryna Maliatsina. Iryna Malacina is a junior researcher and a Ph.D. candidate at the LUT University School of Business and Management. Her main research interests relate to supply network innovation and urban logistics innovation.

CRediT Statement: Conceptualization, Methodology, Validation, Formal Analysis, Writing Original Draft, Writing - Review \& Editing.



Jaan-Pauli Kimpimäki. Jaan-Pauli Kimpimäki is a junior researcher and a Ph.D. candidate at LUT University School of Business and Management. His research interests include the interface of strategy and sustainability considerations with secondary methodological interests in natural language processing and networks of all shapes and sizes.

CRediT Statement: Conceptualization, Methodology, Validation, Formal Analysis, Writing Original Draft, Writing - Review 8 Editing. 